\title{
Obesity and Risk of Myocardial Infarction in Males What is the Best Anthropometric Indicator in the Risk Prediction?
}

\author{
Angel Martin Castellanos* \\ Director of the Nutrition and Sport Medicine Center, Spain
}

Submission: March 05, 2018; Published: April 16, 2018

*Corresponding author: Angel Martin Castellanos, Director of the Nutrition and Sport Medicine Center, Research Group in Bio-Anthropology and Cardiovascular Sciences, University of Extremadura, Faculty of Nursing and Occupational Therapy, Caceres, Spain.

Email: angelmartincastellanos@gmail.com

Keywords : Obesity; Risk; Myocardial; Infarction; Anthropometric; Ischaemic

Abbreviations : BMI: Body Mass Index; WHR; Waist-To-Hip Ratio; WC: Waist Circumference; WHtR: Waist-To-Height Ratio

\section{Introduction}

Cardiovascular diseases are the leading cause of mortality worldwide. On the other hand, ischaemic heart disease is the world`s big killer in males [1]. Worldwide overweight and obesity are an epidemic with high prevalence in adults $[2,3]$. Among anthropometric indicators, body mass index (BMI) has been associated with both cardiovascular mortality and myocardial infarction (MI) [4-6]. But in spite of its wide use is only a surrogate measure of general body fatness and does not provide accurate information on the body composition of risk. However, BMI is the anthropometric health metric proposed to define the construct of ideal cardiovascular health and FusterBEWAT score [7,8], although the real obesity-associated health risk is not absolutely dependent on factors such as lean and bone mass or stature per se. Other indicators such as waist circumference (WC) and waist-to-hip ratio (WHR) are associated to MI with higher discriminative ability [5-9], and WHR has been confirmed as strong indicator to explain risk attributable to obesity $[6,9]$. Thus, WHR was chosen as optimal index of abdominal obesity in the INTERHEART risk score [10]. However, we have demonstrated that the use of WHR for the association of obesity with MI would appear biased if the selected cut of points were not biologically equivalents with other anthropometric indicators as waist-to-height ratio (WHtR) [11].

It is noteworthy that obesity, defined as excess fat mass actually being responsible for most obesity-associated medical conditions but not all individuals at risk of MI are being identified by BMI or WHR [11-12]. It is clear that BMI fails to discriminate between harmful body fat and healthy musculoskeletal component actually being an inappropriate formula to assess the association between excess fat mass and MI $[11,13]$.

Equally, it is well know that hip circumference depends on gluteal mass and gluteal - femoral fat, but it does not discriminate between both components. In this sense, WHR dividing two parallel transversal dimensions has showed lower anthropometric consistency for a causal association than WHtR [11,13]. The somatotype is defined as the quantification of the shape and composition of the human body in discriminating between relative fatness, musculoskeletal component and slenderness [14]. Since the Framingham study, component ratings have been associated with MI although the consistency and biological plausibility must to be well different from each particular component $[11,13,15]$,. Hence, the excessive body weight in individuals who have a high BMI and a normal fat mass (i.e., athletes with high mesomorphy rating) does not influence their cardiovascular risks $[13,16]$.

Other obesity measures such as body fat percentage, WHtR, and conicity have been evaluated in coronary events and mortality prediction with relevant results $[11-12,15,17]$. However, none of these indicators appears as ideal health metric in the individual cardiovascular risk stratifications that include anthropometric variables [7-8,10]. We know that the contribution of anthropometric measures to predict coronary 
risk beyond other cardiovascular risk factors remains controversial. Maybe some of the obesity indicators used as proxies for adiposity assessment may not be the biological risk gold standards. Thus, the anthropometric robustness from BMI and WHR to link both harmful bodily components and cardiovascular risk is unclear and diffuse. Conceptually, each indicator provides its own anthropometric meaning with or without a verifiable and plausible associated biological risk. Ultimately, only a rigorous anthropometric interpretation about the real cardiovascular risk that involve obesity indicators could avoid confusing or paradoxical information, independently of the rest of metrics such as favorable lifestyle and other clinical factors that influence ideal cardiovascular health $[7-8,10]$.

We have explored the association between body composition and obesity in MI to analyze a more consistent anthropometric risk profile $[11,13,17]$. Data still not published would confirm the association discriminative for component ratings and the anthropometric consistency of risk for each obesity indicator. In our research we have demonstrated that both BMI and WHR are not optimal indicators in MI risk prediction, at least in a sample of middle-aged adults that agrees with baseline anthropometric characteristics of those of thousands of European ethnicity infarcted males in the world $[9-11,13]$.

To our knowledge, WC is a suitable proxy measure of visceral adiposity and the nuclear axis for both MI and mortality prediction $[6,11,18]$. Nevertheless, some indices capture higher dimension of risk, although WC always actually being the clear causal part of the anthropometric biological risk in their computational formulas [13]. In addition, an inverse association between height and risk of coronary heart disease has been reported with potential explanations being socioeconomic, genetic even anthropometrics [13,19-20].

However, in a strict anthropometric sense, height does not present hardly plausibility beyond association between shortstature with non-anthropometric factors of atherosclerosis $[13,20]$. We have previously proposed that height factor per se present a weak strength of causal association to MI and it depends on statistical analysis.

Interestingly, height would be a strong modulator factor in the energetic-metabolic balance process and would condition both body composition distribution and MI risk [13]. Height as longitudinal dimension allow us construct WHtR which expresses a quantitative body tridimensional space and the real biological risk by unit of height.

Evidence supports the statistical association for both BMI and WHR with coronary heart disease [6,9,11,21] but information bias may occur $[11,13]$. Overweight and obese people with high mesomorphy rating and/or short-stature could be present higher statistical risk than lean people. Nevertheless, only those with both high whole-body fat and segmental volume of risk would meet anthropometrical criteria for an unhealthy risk association what is unsupported by BMI and WHR in all cases. It is time to shift the anthropometric concept on obesity and their relationship with both nutrition status and risk of coronary disease. In our opinion, an appropriate geographic region-specific and ethnicity-specific WHtR cutoff value would be the easiest anthropometric tool with epidemiological causality criteria, in order to identify nutritional status in adult males at risk of MI.

From strict anthropometric reasons we could say: "Neither body weight nor short- stature or narrow hip is the cause of MI as natural killer in males. Acquired body composition by measuring both WC and height is the first suspect to be kept in mind through an individual body volume ratio that expresses the real component of risk".

\section{References}

1. GBD (2016) Mortality and Causes of Death Collaborators. Global regional and national life expectancy, all-cause mortality, and causespecific mortality for 249 causes of death, 1980-2015: a systematic analysis for the Global Burden of Disease Study 2015. The Lancet 388(10053): 1459-544

2. WHO (2014) Obesity and overweight, Fact sheet No 311.

3. Ng M, Fleming T, Robinson M, Thomson B, Graetz N, et al. (2014) Global, regional, and national prevalenceof overweight and obesity in children and adults during 1980-2013:a systematic analysis for the Global Burden of Disease Study 2013. The Lancet 384(9945): 766-781.

4. Flegal KM, Kit BK, Orpana H, Graubard BI (2013) Association of allcause mortality with overweight and obesity using standard body mass index categories: a systematic review and meta-analysis. JAMA 309(1): 71-82.

5. Carmienke S, Freitag MH, Pischon T, Schlattmann P, Fankhaenel T, et al. (2013) General and Abdominal adiposity parameters and their combination in relation to mortality: a systematic review and metaregression analysis. Eur J Clin Nutr 67(6): 573-585.

6. Yusuf S, Hawken S, Ounpuu S, Bautista L, Franzosi MG, et al. (2005) Obesity and the risk of myocardial infarction in 27,000 participants from 52 countries: a case-control study. The Lancet 366(9497): 16401649.

7. Lloyd-Jones DM, Hong J, Labarthe D, Mozaffarian D, Appel LJ, et al (2010) Defining and Setting National Goals for Cardiovascular Health Promotion and Disease Reduction: The American Heart Association's strategic impact Goal through 2020 and beyond. Circulation 121(4): 586-613.

8. Fernández-Alvira JM, Fuster V, Pocock S, Sanz J, Fernández friera L, et al. (2017) Predicting Subclinical Atherosclerosis in Low-Risk Individuals. Ideal Cardiovascular Health Score and Fuster- BEWAT Score. J Am Coll Cardiol 70(20): 2463-2473.

9. Egeland GM, Igland J, Vollset SE, Sulo G, Eide GE, et al. (2016) High population attributable fractions of myocardial infarction associated with waist-hip ratio. Obesity 24(5): 1162-1169.

10. Martín-Castellanos A, Cabañas-Armesilla MD, Barca-Durán FJ, MartínCastellanos P, Gómez- Barrado JJ (2017) Obesity and risk of Myocardial Infarction in a Sample of European Males. Waist To-Hip-Ratio Presents Information Bias of the Real Risk of Abdominal Obesity. Nutr Hosp 34(1): 88-95.

11. Romero-Corral A, Somers VK, Sierra-Johnson J, Korenfield Y, Boarin S, et al. (2010) Normal weight obesity: a risk factor for cardiometabolic dysregulation and cardiovascular mortality. Eur Heart J 31(6): 737746 
12. Joseph P, Yusuf S, Lee SF, Ibrahim Q Teo K, et al. (2018) Prognostic validation of a non- laboratory and a laboratory based cardiovascular disease risk score in multiple regions of the world. Heart 104(7): 581587.

13. Carter JEL (2002) The Heath-Carter Anthropometric Somatotype Instruction Manual. Department of Exercise and Nutritional Sciencies. San Diego State University: San Diego CA, USA.

14. Zeng Q Dong SY, Sun XN, Xie J, Cui Y (2012) Percent body fat is a better predictor of cardiovascular risk factors than body mass index. Braz J Med Biol Res 45(7): 591-600.

15. Williams SR, Jones E, Bell W, Davies B, Bourne MW (1997) Body habitus and coronary heart disease in men. A review with reference to methods of body habitus assessment. Eur Heart J 18(3): 376-393.

16. Martín-Castellanos A, Cabañas MD, Martín P, Barca FJ. The body composition in myocardial infarction males. Novel findings in both the association and relationship between anthropometric indicators of risk. JONNPR 2(9): 388-398.

17. Martín-Castellanos A (2014) Anthropometric profile, body composition and somatotype study in patients with Acute Coronary

This work is licensed under Creative Commons Attribution 4.0 License

DOI: 10.19080/NFSIJ.2018.06.555685
Syndrome of the Health Area of Caceres. PhD Thesis, Complutense University, Madrid, Spain.

18. Brown JC, Harhay MO, Harhay MN (2017) Anthropometricallypredicted visceral adipose tissue and mortality among men and women in the third national health and nutrition examination survey (NHANES III). Am J Hum Biol 29(1).

19. Yeboach J, Blaha MJ, Michos ED, Qureshi W, Miedema M, et al. (2017) Adult Height, Prevalent Coronary Artery Calcium Score, and Incident Cardiovascular Disease Outcomes in a Multiethnic Cohort. Am J Epidemiol 186(8): 935-943.

20. Nüesch E, Dale C, Palmer TM, White J, Keating BJ, et al. (2016) Adult height, coronary heart disease and stroke: a multi-locus Mendelian randomization meta-analysis. Int J Epidemiol 45(6): 1927-1937.

21. Lassale C, Tzoulaki I, Moons KGM, Sweeting M, Boer J, et al. (2018) Separate and combined associations of obesity and metabolic health with coronary heart disease: a pan-European case-cohort analysis. Eur Heart J 39(5): 397-406.

\section{Your next submission with Juniper Publishers will reach you the below assets}

- Quality Editorial service

- Swift Peer Review

- Reprints availability

- E-prints Service

- Manuscript Podcast for convenient understanding

- Global attainment for your research

- Manuscript accessibility in different formats

( Pdf, E-pub, Full Text, Audio)

- Unceasing customer service

Track the below URL for one-step submission https://juniperpublishers.com/online-submission.php 